\title{
Some Challenges and Potential Issues Regarding Cone Beam Computed Tomography of the Upper Airway
}

\author{
Claudine Thereza-Bussolaro, DDS, OMS, MSc ${ }^{1,2,3,4}$; Camila Pacheco-Pereira, DDS, OMR, MSc, Ph.D. candidate ${ }^{4,5}$; Manuel \\ Lagravère, DDS, BSc, MSc, DSc ${ }^{4}$; Carlos Flores-Mir, DDS, BSc, MSc, DSc ${ }^{4}$ \\ ${ }^{1}$ Professor of Dentistry, UNIFASIPE, Sinop, Brazil; ${ }^{2}$ Graduate Program Coordinator, CEOF/FAIPE, Sinop, Brazil; ${ }^{3}$ Oral Maxillofacial \\ Surgeon, Hospital Dois Pinheiros, Sinop, Brazil; ${ }^{4}$ Faculty of Medicine and Dentistry, University of Alberta, Edmonton, Canada; \\ ${ }^{5}$ University of Texas Health Sciences Center at San Antonio, Texas, United States
}

\begin{abstract}
Breathing is essential for human survival. During clinical and intraoral evaluations, dentists can identify some phenotypic characteristics that have been linked to sleep-disordered breathing (SDB). Therefore, dentists could be engaged in screening and, when indicated, refer patients with high risk for obstructive sleep apnea (OSA) to appropriate medical specialists for a full diagnosis. Participation by the dentists in future interdisciplinary management can follow. Although cone-beam computed tomography (CBCT) is an established imaging modality in dentistry, it still carries some challenges related to volume rendering management and interpretation. This article outlines the challenges of assessing available CBCT and the use of commercially available rendering tools of the upper airway. The focus of this article is on important considerations regarding the use of this advanced imaging modality for nasopharyngeal obstruction assessments and volume reconstructions. It is suggested that dentists have an essential role in SDB screening, and when CBCT is already available, it could be used as a complementary tool for volumetric airway assessment. Such involvement implies the need for a more robust understanding of current CBCT imaging limitations and potential. Finally, the role of three-dimensional printing from upper airway three-dimensional imaging for educational purposes in dentistry is discussed.
\end{abstract}

Keywords: CBCT, dentistry, sleep medicine, three-dimensional printing, upper airway obstruction

Citation: Thereza-Bussolaro C, Pacheco-Pereira C, Lagravère M, Flores-Mir C. Some challenges and potential issues regarding cone beam computed tomography of the upper airway. J Dent Sleep Med. 2021;8(2)

\section{INTRODUCTION}

Sleep-disordered breathing (SDB) includes a spectrum of clinical entities such as primary snoring, upper airway resistance syndrome, obstructive hypoventilation, and obstructive sleep apnea (OSA). ${ }^{1-3}$ Upper airway obstruction and nasal craniofacial anomalies are accountable traits for the occurrence of OSA. ${ }^{4-6}$ The consequences of not promptly addressing this public health issue have been extensively explored.,.$^{3,7,9,10,11}$ Therefore, better integration and coordination between the dental and medical communities to address SDB- related issues would likely benefit patients. ${ }^{12}$

Dentists are responsible for the diagnosis, treatment, and prevention of diseases and disorders of the oral cavity and related structures. ${ }^{12}$ They may also play an essential role $^{13}$ in screening and referring potential patients with high-risk factors for SDB because the evaluation of the oral cavity, airway patency, and neck circumference can be readily performed in dental practices. ${ }^{14}$ Sometimes dental evaluations followed by radiographic images can also serve as a screening source for some chronic diseases, including SDB entities. ${ }^{12}$

Flexible nasopharyngoscopy (nasal endoscopy, NE) and magnetic resonance imaging are the most common methods used to complement the clinical assessment of the upper airway region because of its dynamic process. Some studies have acknowledged that CBCT is becoming an imaging choice for dentists during upper airway assessment, ${ }^{15-17}$ even though CBCT has shortcomings, for awake patients an in upright position. As an example, the use of available CBCT to screen for adenoid hypertrophy (AH) has shown a level of agreement between CBCT and NE. ${ }^{15,18}$ Nevertheless, appropriate three-dimensional (3D) volume rendering is still a challenge in the CBCT field. ${ }^{15,19,20}$

In dentistry, the use of CBCT 3D technology and image reconstruction is more common in the fields of oral maxillofacial surgery, implantology, and orthodontics. 3D printing is an advanced cutting-edge technology that allows the rapid conversion of information from digital 3D models into 3D physical objects. ${ }^{21-24}$ The possibilities of this imaging type in other disciplines still require further development and justification. Limited related knowledge by dentists could lead to a lack of familiarity with normal and abnormal features, which can compromise the diagnostic suspicions they can provide. In other words, some exposure is good, but with a clear understanding of the need for further training the more this type of technology is used.

The objective of this article is to address the challenges regarding CBCT's volume rendering and the potential of the $3 \mathrm{D}$ technology and printing technology in the dental field as related to SDB. 
Figure 1. Example of the effect of the sensitivity threshold adjustment in measurement and three-dimensional reconstruction surface in Dolphin software. Reproduced from Thereza-Bussolaro $C$, Lagravère $M$, Pacheco-Pereira $C$, Flores-Mir C. Development, validation and application of a 3D printed model depicting adenoid hypertrophy in comparison to a nasoendoscopy. Head Face Med. 2020;16(1):1-8.

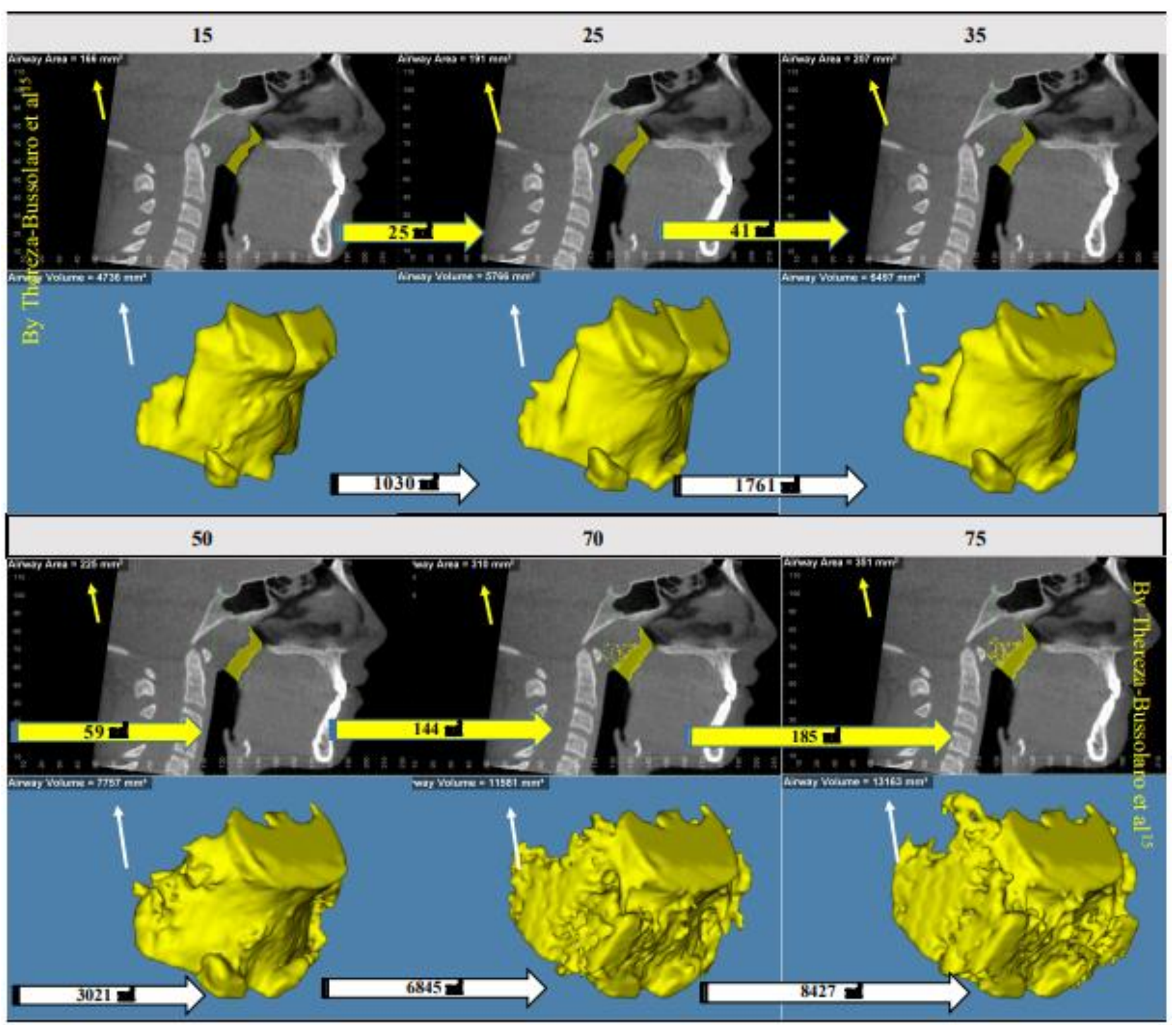

yellow arrow indicate the changing in area measurements, and white arrow indicate the changes in volume measurements.

\section{CBCT'S VOLUME RENDERING CHALLENGES}

The use of CBCT images for upper airway analysis through volume rendering has been used for more than a decade. $^{25-27}$ It should be emphasized that using CBCT images exclusively for diagnosis of the airway is not the standard protocol and should not be encouraged because of the increased ionization radiation and the relative limitations of static imaging of a dynamic scenario. However, CBCT has been explored and suggested as an adjunctive upper airway evaluation. Nevertheless, the management of density values, also known as gray thresholding, is still a challenge in the CBCT field, ${ }^{15}$ and the need for adjustment of the threshold levels has been explored to obtain less variation during the imaging asesesment. ${ }^{15,19,20}$

Density values derive from Hounsfield unit (HU) selection, which is still a significant limitation for the imaging field of upper airway CBCT. For instance, some software has a sensitivity tool, named "HU", to identify the density value in the scan. Still, its value does not correspond to the specific HU value of 0 for water and 1000 for air expressly set for medical CT machines. ${ }^{28}$ In addition, the shortcomings of the CBCT acquisition, such as having the patient awake and in an upright position, should be considered. 
Figure 2. Cone beam computed tomography parameters variation in upper airway studies.

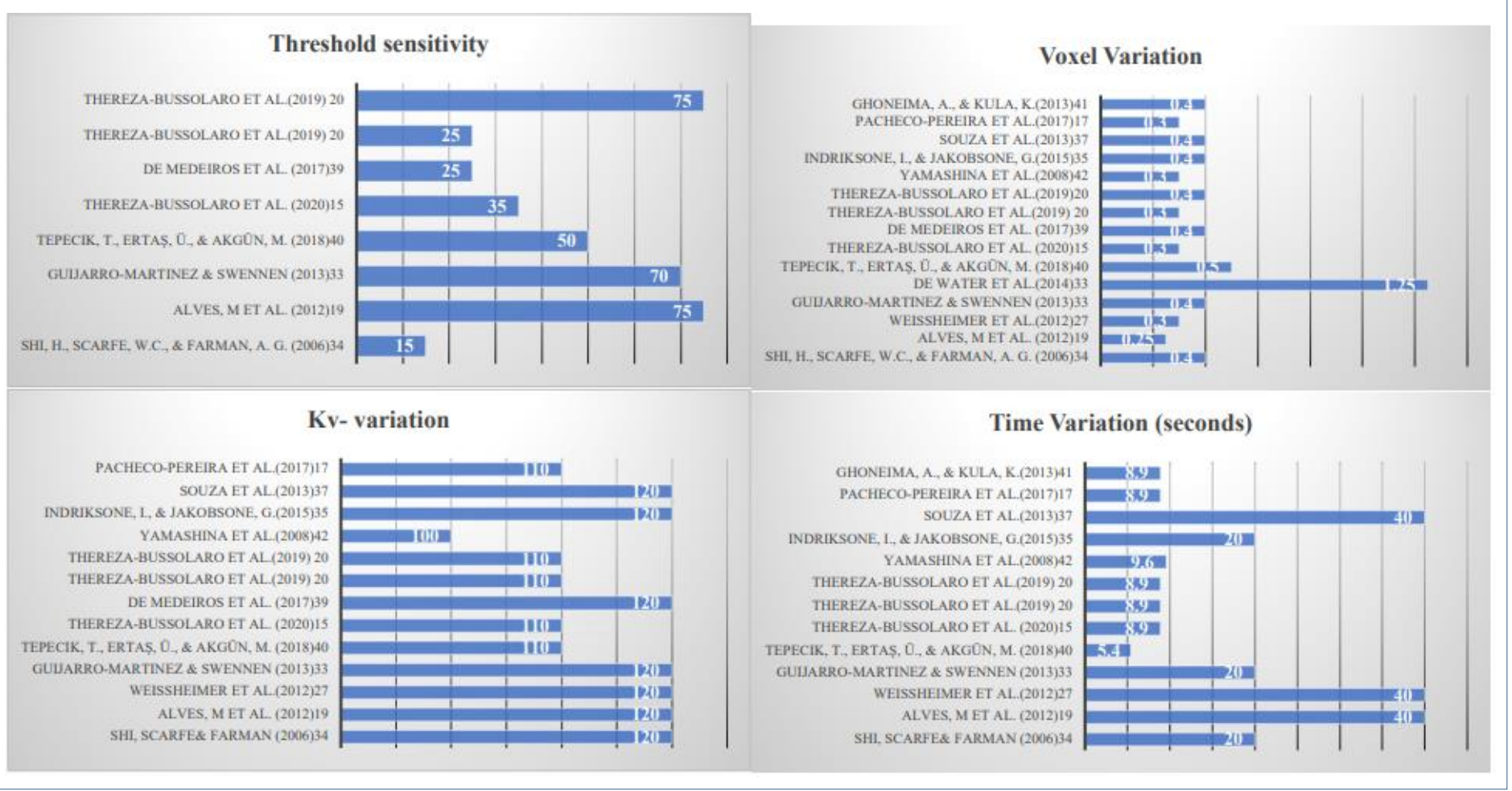

It has been reported that the thresholding preestablished during an automatic segmentation, for the depiction of the open airway, is the leading cause of its considerable variation compared to manual segmentation. ${ }^{29,30}$ The use of different thresholds even for other anatomic sites has been suggested. ${ }^{29}$ Regarding the depiction of soft tissue, only one study ${ }^{15}$ reported depicting the soft tissue (uvula and surrounding region), and the HU values maintained the same threshold of 561 for the lower bound and fluctuated between 3052 to 3250 for the upper bound.

In a recent study, ${ }^{15}$ the authors provided a literature review on airway-based studies using Dolphin software Dolphin 3D, version 11.95 premium, Dolphin imaging \& management Solutions, Chatsworth, CA, USA. Six studies ${ }^{19,20,30-33}$ reported adjustment of the threshold values for the depiction of the air-filled "airway". The authors concluded that even under similar conditions, the selection of the cutoff could have a significant bearing on the volume measurement results as well as the $3 \mathrm{D}$ surface. To simulate the effect of the changes, a pilot scenario was created with six threshold values $(15,25,35,50,70$, and $75 \mathrm{HU})$ in the same patient in the same landmark area, and surface volume distortions were observed ${ }^{15}$ (Figure 1).

A disparity in CBCT scanning parameters such as exposure time, tube current (mA), voxel size, and tube voltage has also been observed among airway studies. ${ }^{15,17,20,31,33-42}$ This variation could also affect volume rendering. Dentists, unaware of such technical information, are prone to interpretation errors. Scanning parameters variation in upper airway studies is depicted in Figure 2.

\section{D PRINTING IN DENTISTRY}

$3 \mathrm{D}$ printing is a technology that converts a multidimensional image to a physical 3D model, enabling a more comprehensive study of human anatomic structures, especially complex anatomies. Because 3D printed models are capable of providing tactile feedback and actual depth information about anatomic and pathologic cases, it could work to help educate dentists about the normal nasopharynx anatomy and its variations and raise awareness in affected patients about the importance of looking for a specialist. ${ }^{22}$

The number of studies in dentistry exploring the use of CBCT-3D printing for upper airway is still limited. In 2012, a study reported on a prototype of the oropharynx using MIMICS software (Materialize NV, Leuven, Belgium), and from that evaluated the sensitivity threshold using Dolphin software. ${ }^{19}$ The authors of another study printed the oropharynx space and compared the accuracy between multidetector $\mathrm{CT}$ and $\mathrm{CBCT} .{ }^{43}$ It was concluded that CBCT scanners offer an alternative to multidetector CT in the assessment of the oropharynx morphology. Additionally, the authors of a recent study ${ }^{15}$ developed and validated the use of $3 \mathrm{D}$ printed models of the nasopharyngeal area of patients with different degrees of $\mathrm{AH}$, which has a prevalence ranging from $42 \%$ to $70 \%{ }^{44}$ in a convenience sample and is the most common cause of upper airway obstruction in children. This study explored CBCT scan reconstructions, from available CBCTs, through Dolphin software as a mechanism to screen for $\mathrm{AH}$ in comparison with oral head and neck specialist direct NE 
Table 1. Studies reporting 3D printed prototypes of the upper airway

\begin{tabular}{lllll}
\hline Author & Year & Country & Clinical Field & Software \\
\hline Alves, M et al. ${ }^{19}$ & 2012 & Brazil & Orthodontics & Mimics \\
Chen et al. $^{43}$ & 2018 & Netherlands & Radiology/Oral maxillofacial surgery & Amira \\
Thereza-Bussolaro et al. $^{15}$ & 2020 & Canada & $\begin{array}{l}\text { Oral maxillofacial Surgery/ } \\
\text { Radiology/Orthodontics* }\end{array}$ & Dolphin \\
\hline \hline
\end{tabular}

*screening purpose

assessment of the area. The prototype used, representing the adenoid and surrounding anatomy, showed 100\% sensitivity and $70 \%$ specificity level, therefore correctly identifying enlarged adenoids with only $5 \%$ of falsenegative cases. The authors concluded that both twodimensional and 3D representations of the nasopharyngeal obstructed area could be a practical alternative for the assessment of the nasopharyngeal adenoidal obstruction. ${ }^{15}$ Table 1 presents a list of studies that have explored 3D printing of the upper airway.

\section{D PRINTING FOR EDUCATIONAL PURPOSES}

The ability to re-create patient-specific scenarios makes 3D printing a new technology in constant evolution as a health education tool. Understanding the learning gap is the first step to create a new tool for educational purposes, which can include a variety of topics from anatomic teaching to simulation procedures. ${ }^{45,46}$

In dental education, the use of training models has been established. However, there is still a lack of educational materials to transfer practical skills on exact replicas to a real patient situation. Recently, the use of CBCT-3D printing for these detailed simulations has been successfully explored. ${ }^{47-50}$ In 2010, haptic patient models were developed to teach the relationship between the third molar and the inferior mandibular nerve. ${ }^{47}$ In 2018, studies were done in the oral maxillofacial field..$^{48,49}$ One study ${ }^{48}$ simulated impacted third molar and sinus lift surgeries prototypes, and another ${ }^{49}$ explored 3D printing on handson training courses on dental traumatology for undergraduate students in their final year. Finally, in a 2019 study with students of endodontic dentistry, root canal treatment was performed on printed molars. ${ }^{50}$ It is believed that $3 \mathrm{D}$ printing from $\mathrm{CBCT}$ is a promising method for training residents or dental students.

\section{SUMMARY}

Dentists' learning gaps in screening for nasopharyngeal obstruction in CBCT could be addressed with the exploration of $3 \mathrm{D}$ depiction tools ${ }^{15}$ not only as a screening tool for nasopharyngeal obstruction but as an alternative for its study and education. This is because these tools are capable of providing tactile feedback and precise depth information about anatomic and pathologic cases.

It is important to stress that CBCT is not the reference standard of care for OSA, and the current diagnosis must be made by a physician based on clinical examination and polysomnography. Furthermore, the dentist's role in these cases is to refer patients for proper assessment. Other imaging modalities reflecting the dynamics of the airway, such as dynamic upper airway CT and functional magnetic resonance imaging, could better represent the narrowing of the airway space.

The assessment of upper airway obstruction in patients at risk for SDB is essential to support adequate interdisciplinary management. Timely intervention may likely prevent any further significant health consequences. CBCT, when already available, could help streamline the referral process to a specialist in medical SDB. For this reason, awareness regarding sensitivity tools and imaging limitations in CBCT should be raised among dentists. Finally, it can be debated that there is potential in the use of $3 \mathrm{D}$ depiction tools in dentistry as teaching tools that should be further explored.

\section{ABBREVIATIONS}

3D- Three dimensional

AH - Adenoid hypertrophy

CBCT - Cone-beam computed tomography

HU - Hounsfield unit scale

NE - Nasal endoscopy

OSA - Obstructive sleep apnea

SDB - Sleep-disordered breathing

\section{REFERENCES}

1. Cistulli P, Sullivan C. Pathophysiology of sleep apnea. Lung Biology in Health and Disease. 1994;71:405-448.

2. McNamara S, Cistulli P, Sullivan C, Strohl K. Clinical aspects of sleep apnea. Lung Biology in Health and Disease. 1994;71:493-528.

3. R. G, Licameli, Tunkel, E. D. Infectious and Inflammatory Disorders 
of the Tonsils and Adenoid. In: R. G, Licameli, Tunkel, E. D, editors. Pediatric otorhinolaryngology: diagnosis and treatment Chapter 6: Thieme; 2013.

4. Lavigne G, Herrero Babiloni A, Beetz G, et al. Critical issues in the dental and medical management of obstructive sleep apnea. J Dent Res. 2020;99(1):26-35.

5. Cistulli PA. Craniofacial abnormalities in obstructive sleep apnoea: implications for treatment. Respirology. 1996;1(3):167-174.

6. Eckert DJ. Phenotypic approaches to obstructive sleep apnoea-new pathways for targeted therapy. Sleep Med Rev. 2018;37:45-59.

7. Papaioannou G, Kambas I, Tsaoussoglou M, PanaghiotopoulouGartagani P, Chrousos G, Kaditis AG. Age-dependent changes in the size of adenotonsillar tissue in childhood: implications for sleepdisordered breathing. J Pediatr. 2013;162(2):269-274. e264.

8. Kaditis AG, Alvarez MLA, Boudewyns A, et al. Obstructive sleep disordered breathing in 2-to 18-year-old children: diagnosis and management. Eur Respir J. 2016;47(1):69-94.

9. Ehsan Z, Ingram DG. Economic and social costs of sleep apnea. Curr Pulmonol Rep. 2016;5(2):111-115.

10. Clarke J. Difficulty accessing health care services in Canada. In: Canada S, editor.: Statistics Canada Ottawa, Ontario, Canada; 2016.

11. Barua B, Esmail N, Jackson T. The effect of wait times on mortality in Canada. Vancouver: Fraser Institute 2014. p. 78.

12. Gambhir RS. Primary care in dentistry - an untapped potential. $J$ Family Med Prim Care. 2015;4(1):13-18.

13. Gianoni-Capenakas S, Gomes A, Mayoral P, Miguez M, Pliska B, Lagravere M. Sleep-disordered breathing: The dentists' role-A systematic review. J Dent Sleep Med. 2020;7(1).

14. Major M, El-Hakim H, Witmans M, Major P, Flores-Mir C. Adenoid hypertrophy in pediatric sleep disordered breathing and craniofacial growth: the emerging role of dentistry. J Dent Sleep Med. 2014;1(2):83-87.

15. Thereza-Bussolaro C, Lagravère M, Pacheco-Pereira C, Flores-Mir C. Development, validation and application of a 3D printed model depicting adenoid hypertrophy in comparison to a Nasoendoscopy. Head Face Med. 2020;16(1):1-8.

16. Schwab RJ. Upper airway imaging. Clin Chest Med. 1998;19(1):3354.

17. Pacheco-Pereira C, Alsufyani N, Major M, Palomino-Gomez S, Pereira JR, Flores-Mir C. Correlation and reliability of cone-beam computed tomography nasopharyngeal volumetric and area measurements as determined by commercial software against nasopharyngoscopy-supported diagnosis of adenoid hypertrophy. Am J Orthod Dentofacial Orthop. 2017;152(1):92-103.

18. Major MP, Witmans M, El-Hakim H, Major PW, Flores-Mir C. Agreement between cone-beam computed tomography and nasoendoscopy evaluations of adenoid hypertrophy. Am J Orthod Dentofacial Orthop. 2014;146(4):451-459.

19. Alves Jr M, Baratieri C, Mattos CT, et al. Is the airway volume being correctly analyzed? Am J Orthod Dentofacial Orthop. 2012;141(5):657-661.

20. Thereza-Bussolaro C, Oh HS, Lagravère M, Flores-Mir C. Pharyngeal dimensional changes in class II malocclusion treatment when using Forsus ${ }^{\circledR}$ or intermaxillary elastics - An exploratory study. Int Orthod. 2019;17(4):667-677.

21. Roopavath UKK, Deepak M. 3D Printing in Medicine. First Edition ed: Elsevier; 2017 April 2017. 1-17 p.

22. Mitsouras D, Liacouras P, Imanzadeh A, et al. Medical 3D printing for the radiologist. Radiographics. 2015;35(7):1965-1988.

23. Charangowda B. Dental records: An overview. J Forensic Dent Sci. 2010;2(1):5-10.

24. Steen LH. Design and validation of a practical simulator for the development of basic nasal endoscopy skills in otolaryngology - head and neck surgery [Manuscript]: University of Alberta; 2015. ")

25. Aboudara C, Nielsen I, Huang JC, Maki K, Miller AJ, Hatcher D. Comparison of airway space with conventional lateral headfilms and 3-dimensional reconstruction from cone-beam computed tomography. Am J Orthod Dentofacial Orthop. 2009;135(4):468479 .

26. Fourie Z, Damstra J, Gerrits PO, Ren Y. Accuracy and reliability of facial soft tissue depth measurements using cone beam computer tomography. Forensic Sci Int. 2010;199(1):9-14.

27. Periago DR, Scarfe WC, Moshiri M, Scheetz JP, Silveira AM, Farman AG. Linear accuracy and reliability of cone beam CT derived 3-dimensional images constructed using an orthodontic volumetric rendering program. Angle Orthod. 2008;78(3):387-395.

28. Hounsfield GN. Computerized transverse axial scanning (tomography): Part 1. Description of system. Br J Radiol. 1973;46(552):1016-1022.

29. Alsufyani NA, Noga ML, Witmans M, Major PW. Upper airway imaging in sleep-disordered breathing: role of cone-beam computed tomography. Oral Radiology. 2017:1-9.

30. Valerie R, Saridin JK, Bouw F, Murawska MM, Koudstaal MJ. Measuring upper airway volume: accuracy and reliability of Dolphin 3D software compared to manual segmentation in craniosynostosis patients. J Oral Maxillofac Surg. 2014;72(1):139-144.

31. Pinheiro ML, Yatabe M, Ioshida M, Orlandi L, Dumast P, TrindadeSuedam IK. Volumetric reconstruction and determination of minimum crosssectional area of the pharynx in patients with cleft lip and palate: comparison between two different softwares. J Appl Oral Sci. 2018;26:e20170282 .

32. Weissheimer A, de Menezes LM, Sameshima GT, Enciso R, Pham J, Grauer D. Imaging software accuracy for 3-dimensional analysis of the upper airway. Am J Orthod Dentofacial Orthop. 2012;142(6):801-813.

33. Guijarro-Martinez R, Swennen GR. Three-dimensional cone beam computed tomography definition of the anatomical subregions of the upper airway: a validation study. Int J Oral Maxillofac Surg. 2013;42(9):1140-1149.

34. Shi H, Scarfe WC, Farman AG. Upper airway segmentation and dimensions estimation from cone-beam CT image datasets. Int $J$ Comput Assist Radiol Surg. 2006;1(3):177-186.

35. Indriksone I, Jakobsone G. The influence of craniofacial morphology on the upper airway dimensions. Angle Orthod. 2015;85(5):874-880.

36. Rebong RE, Stewart KT, Utreja A, Ghoneima AA. Accuracy of three-dimensional dental resin models created by fused deposition modeling, stereolithography, and Polyjet prototype technologies: A comparative study. Angle Orthod. 2018;88(3):363-369.

37. Souza KR, Oltramari-Navarro PV, Navarro Rde L, Conti AC, Almeida MR. Reliability of a method to conduct upper airway analysis in cone-beam computed tomography. Braz Oral Res. 2013;27(1):48-54.

38. de Water VR, Saridin JK, Bouw F, Murawska MM, Koudstaal MJ. Measuring upper airway volume: accuracy and reliability of Dolphin 3D software compared to manual segmentation in craniosynostosis patients. J Oral Maxillofac Surg. 2014;72(1):139-144.

39. de Medeiros JR, Bezerra MF, Costa FG, Bezerra TP, de Araújo Alencar C, Soares ES. Does pterygomaxillary disjunction in surgically assisted rapid maxillary expansion influence upper airway volume? A prospective study using Dolphin Imaging 3D. Int J Oral Maxillofac Surg. 2017;46(9):1094-1101.

40. Tepecik T, Ertaş Ü, Akgün M. Effects of bimaxillary orthognathic surgery on pharyngeal airway and respiratory function at sleep in patients with class III skeletal relationship. J Cranio-Maxillofac Surg. 2018;46(4):645-653.

41. Ghoneima A, Kula K. Accuracy and reliability of cone-beam computed tomography for airway volume analysis. Eur J Orthod. 2013;35(2):256-261. 

reliability of computed tomography (CT) values and dimensional measurements of the oropharyngeal region using cone beam CT: comparison with multidetector CT. Dentomaxillofac Radiol. 2008;37(5):245-251.

43. Chen H, van Eijnatten M, Aarab G, et al. Accuracy of MDCT and CBCT in three-dimensional evaluation of the oropharynx morphology. Eur J Orthod. 2018;40(1):58-64.

44. Pereira L, Monyror J, Almeida FT, et al. Prevalence of adenoid hypertrophy: A systematic review and meta-analysis. Sleep Med Rev. 2018;38:101-112.

45. Garcia J, Yang Z, Mongrain R, Leask RL, Lachapelle K. 3D printing materials and their use in medical education: a review of current technology and trends for the future. BMJ Simul Technol Enhanc Learn. 2018;4(1):27-40.

46. McMenamin PG, Quayle MR, McHenry CR, Adams JW. The production of anatomical teaching resources using three-dimensional (3D) printing technology. Anat Sci Edu. 2014;7(6):479-486.

47. Lambrecht J, Berndt D, Christensen A, Zehnder M. Haptic model fabrication for undergraduate and postgraduate teaching. Int J Oral Maxillofac Surg. 2010;39(12):1226-1229.

48. Werz S, Zeichner S, Berg BI, Zeilhofer HF, Thieringer F. 3D printed surgical simulation models as educational tool by maxillofacial surgeons. Eur J Dent Educ. 2018;22(3):e500-e505.

49. hands-on training in dental traumatology. Int Endod J. 2018;51(11):1313-1319.

50. Reymus M, Fotiadou C, Kessler A, Heck K, Hickel R, Diegritz C. 3D printed replicas for endodontic education. Int Endod J. 2019;52(1):123-130.

\section{SUBMISSION \& CORRESPONDENCE INFORMATION}

\section{Submitted in final revised form November 7, 2019 Accepted for publication October 25, 2020}

Address correspondence to: Claudine TherezaBussolaro, DDS, OMS, MSc, Av dos Tarumas, 995, sala 12, cep 78556-404, Sinop-MT, Brasil. Phone number: +55(66)99205-0080; E-mail address: bussolar@ualberta.ca.

\section{DISCLOSURE STATEMENT}

The authors have no conflicts of interest to disclose. 